
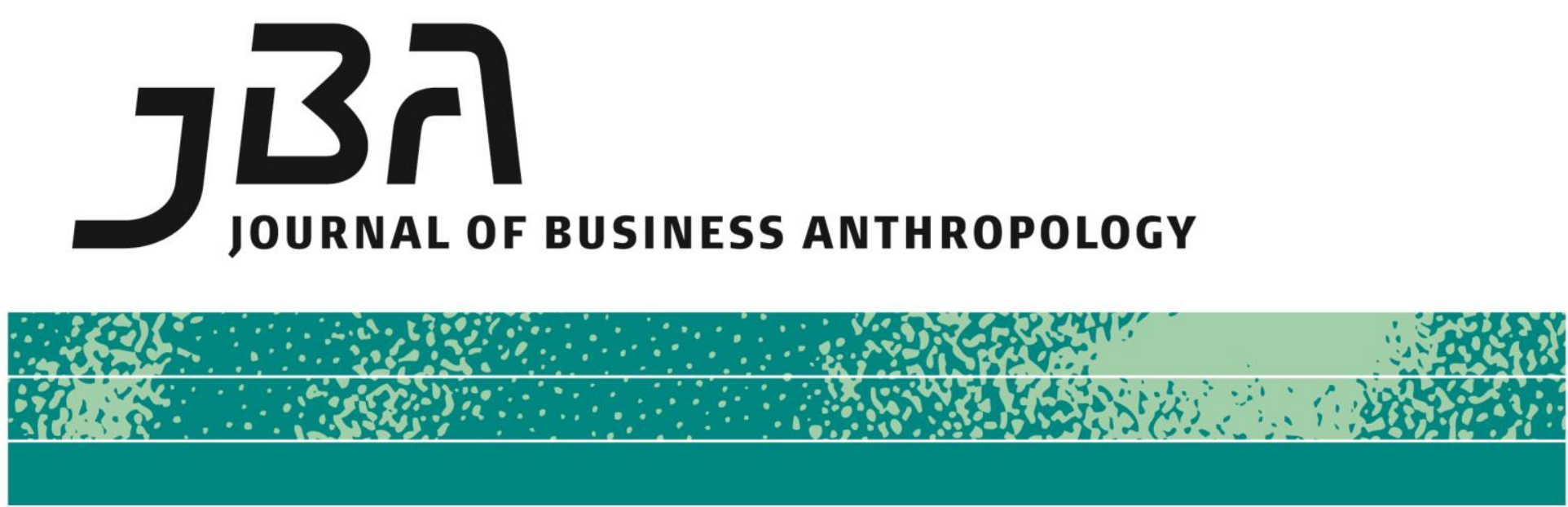

\title{
"No More Cakes and Ale?" Discovering Ethical Gray Areas in a Design Anthropology Class
}

Jo Aiken, Victoria Schlieder, and Christina Wasson

\begin{abstract}
This article examines how ethics were learned in a design anthropology class. Training in ethics is an essential part of any graduate program in anthropology, and we show how it was built into this course. At the same time, the fieldwork that students conducted as part of a client project for Motorola confronted some of them with unexpected and ethically ambiguous circumstances, which generated experiential learning as well. Regardless of how clearly ethical codes are written, researchers will always encounter gray areas in the field. The article presents a case study of one study participant who may have been intoxicated, analyzing this as an "extreme case" that brought ethical dilemmas into sharp focus. We conclude with suggestions for navigating ethical gray areas, based on class discussions about this and other ethical challenges.
\end{abstract}

\section{Keywords}

Design anthropology, ethics, fieldwork, pedagogy, business anthropology
Page 1 of 24

JBA Special Issue 1: 38-61, Spring 2014

(C) The Author(s) 2014 ISSN 2245-4217

www.cbs.dk/jba 
"Dost thou think, because thou art virtuous, there shall be no more cakes and ale?"

Sir Toby in Shakespeare's Twelfth Night, Act 2, Scene 3

\section{Introduction}

In recent years, business anthropologists have increasingly turned their attention to the issue of training the next generation of practitioners (Ikeya et al. 2007, Mack and Squires 2011, Tian 2011, Wasson and Metcalf 2013). ${ }^{1}$ While the first generation of business anthropologists was largely trained in traditional academic programs that provided no guidance on the challenges of working in industry, a number of master's and Ph.D. programs have recently emerged that focus specifically on preparing anthropology students for careers in the business context (Sachs 2006, Squires et al. 2014). Examples include programs at Wayne State University, the University of Copenhagen, and the University of North Texas (UNT).

Training in ethics is an essential component of any graduate program in anthropology (Fluehr-Lobban 2003, Kingsolver et al. 2003). And while learning about professional codes of ethics is a valuable starting point, programs need to go further. Students need to learn how to navigate ethical complexities, contradictions, and ambiguities that cannot be fully captured by such codes. Fluehr-Lobban argues that recognizing the limitations of ethics codes is the "real job of ethics education through the critical study of the history of the discipline and ... the review of cases, past and present, for the lessons they offer regarding fieldwork methods, relations with people and materials studied, and with stakeholders" (2003:23). As Shakespeare's Sir Toby points out to the Puritannical Malvolio in the quote at the start of this article, not everyone shares the same understanding of virtuous or ethical behavior. Even the most virtuous anthropologist, striving for the highest moral standards, may still encounter ethically gray areas with research participants who are enjoying their "cakes and ale," leading lives according to their own preferences in ways that may create dilemmas for the researchers.

\footnotetext{
${ }^{1}$ We would like to extend our deep appreciation to Tim Malefyt and Robert Morais for organizing the 2012 session on ethics in business anthropology where this research was originally presented, and for guiding us gracefully through the editing process. The comments of our anonymous reviewers improved the article immeasurably. Finally, we wish to thank Crysta Metcalf, our research participants, and all of the other students in the 2011 design anthropology class for collaboratively creating such a rich and rewarding learning experience.
} 
In this article, we examine how a consideration of ethics has been incorporated into one course in the UNT business anthropology program, namely Design Anthropology. This course is a core elective in the UNT business anthropology specialization, and it is the only course on design anthropology offered by an anthropology department in the United States (Wasson and Metcalf 2013). Specifically, we focus on the course as it was taught in fall 2011. Authors include two students from the class (Aiken, Schlieder) and the instructor (Wasson).

Students in the Design Anthropology course learned about ethics through initial class discussions, safeguards that the instructor built into the course, and guidelines on the disclosure of findings. Most importantly, they gained hands-on experience in negotiating ethical challenges through the experience of conducting ethnographic fieldwork for a client project. In this article, we focus on one particular example of an ethical challenge faced by student researchers, and its pedagogical value as an extreme case (LeCompte and Schensul 1999:113, Yin 2009:47). In this example, a team of student researchers was faced by multiple pressures and challenges simultaneously, and had to navigate a course in the face of ambiguity and an inability to communicate with each other privately. While this kind of "perfect storm" of problems may not occur frequently, it provided a valuable learning experience for the class. As the students in the class collectively analyzed the case afterwards, they came to recognize that gray areas inevitably arise in the course of fieldwork, and that such areas do not always have tidy solutions. Nonetheless it is important for researchers to be sensitive to all of the ethical dimensions of their field activities, and to search for the most ethical path possible through them.

The dilemma that provides the case study for this article contributes to a long tradition of anthropologists writing about ethical challenges encountered during fieldwork. Often these narratives are found in books that present personal stories of the author's experience (Armbruster and Laerke 2008, Bowen 1954, Golde 1970, Moeran 1985, Powdermaker 1966). These stories highlight the experiential, emergent dimensions of fieldwork in which researchers are fully, often anxiously, engaged in trying to understand local people, activities, and contexts, but often unsure about their meanings. In this sense, fieldwork encounters may be analyzed as "modes of ethical engagement wherein the ethnographer is arrested in the act of perception. This arrest can lead both to a productive doubt about the ongoing perception of the phenomena in interaction and to the possibility of elaborating shared knowledge" (Borneman and Hammoudi 2009:19). In this sense, the examination of an ethical dilemma may produce broader insights about the cultural worlds of both the anthropologist and the research participants, and the complex, imperfect, and emotionally laden process of attempting to create translations between them. 


\section{Overview of course and client project}

A key aspect of the pedagogy of the Design Anthropology course, as Wasson has designed it, is that students engage in a semester-long research project for a real client. Usually about half the class time is devoted to project activities, while the other half is taken up with critical analysis of the design anthropology literature. The research project provides a rich forum for students to debate ethical issues during the planning stages, and to gain practical experience in solving ethical challenges during fieldwork.

In fall 2011, the client for the project was Motorola Mobility's Applied Research Center, represented by Crysta Metcalf, Anthropologist and Manager of Experiences Research. Metcalf was an active partner throughout the process; she played a strong role in shaping the project goals and design before the class started, and provided feedback during the semester to keep the class focused on what was most useful to Motorola Mobility. Metcalf participated in weekly class meetings via phone and shared computer applications, and visited the class in person three times over the course of the semester. The fall 2011 project was in fact the fifth such collaboration between Metcalf and Wasson (Wasson and Metcalf 2013).

The research conducted for Motorola Mobility was an exploratory study of how people use media to enhance their cooking experience. The goal was to elicit new ideas for Motorola applications and services in the kitchen. Students investigated how multimedia devices were being used in the kitchen/cooking context before, during, and after the food-making process. Findings included, for example, a set of sample trajectories of cooking experiences (see Figure 1) that Motorola could use to understand where the most media usage occurred. The "Omelet Trajectory" shown in Figure 1 indicates that before beginning to cook, many participants looked up a recipe on the internet (using any kind of media device). During a cooking experience, they might have the television on for background noise, or even to watch a cooking show. Similarly, some participants watched instructional videos on the internet during a cooking experience, to learn the skills needed. After someone was done with a particular cooking experience, they might use the internet to share their story, especially if they were proud of their final product. 


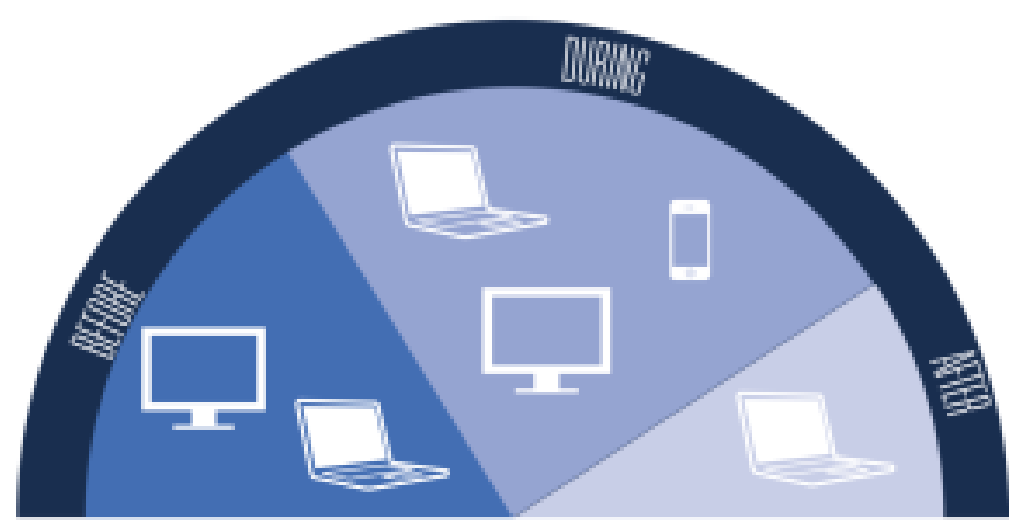

MICHAEL'S OMELET TRAJECTORY

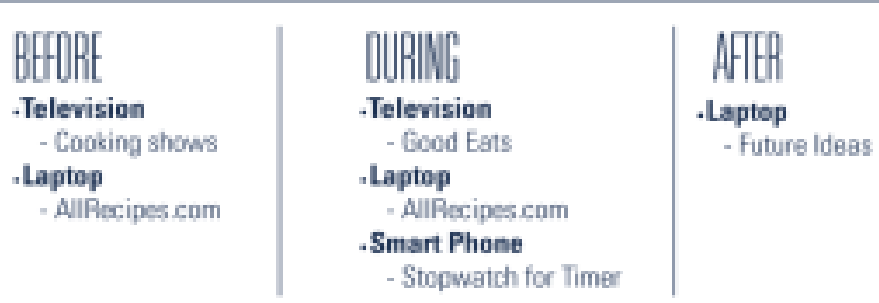

Figure 1: The Omelet Trajectory

As noted in a project overview document prepared by Crysta Metcalf, the kitchen is often described as "the heart of the home," and much research has been done on family activities in the kitchen. Most ideas for technology innovations that have resulted from such research revolve around family calendars, ways of coordinating and keeping track of family activities, and so on. Yet much of what is done in the kitchen is food preparation. Metcalf believed that there was an opportunity to discover and understand people's needs and desires around the specific activity of cooking, and to invent new applications and services that could address those needs.

Wasson generally restricts admission to the design anthropology class to anthropology and design students, both advanced undergraduates and master's level students. However, she also allows PhD students in related fields to participate. In fall 2011, the 16 students consisted of:

- 5 undergraduate anthropology majors

- 2 undergraduate communication design majors

- 1 undergraduate interdisciplinary arts and design/anthropology double major

- 3 MA students in anthropology

- 2 MFA and 1 MA students in communication design

- $1 \mathrm{PhD}$ student in marketing

- $1 \mathrm{PhD}$ student in education 
The class was therefore mainly a mix of anthropology and design students, with a few students from other fields for additional diversity and insights. In conducting fieldwork, students were required to work in interdisciplinary pairs. This mix produced a productive learning experience for all participants, and the project benefited from the expertise of each discipline.

The interdisciplinary diversity of students had implications with regard to ethics, since each discipline has evolved ethical norms particular to its concerns (Balsamo and Mitchell 2012). While the centerpiece of anthropological codes is the imperative to protect research participants from harm (AAA 2012, SfAA 2013, NAPA 2013), design codes do not address the treatment of research participants at all, since historically human research was not a part of design activities (AIGA 2010, IDSA 2010). However, the Department of Design at UNT focuses on the emerging field of design research, which borrows extensively from anthropology and other social sciences. Therefore, while most anthropology students were probably more familiar with the topic of ethics, the design students had already been sensitized to the challenges of conducting fieldwork.

The most recent code of the American Anthropological Association recognizes the challenges of interdisciplinary collaboration, stating that "conflicting, competing or crosscutting ethical obligations" may result from "differing ethical frameworks of collaborators representing other disciplines" (2012:9). We would not go so far as to say that students experienced conflicts between disciplinary ethical principles. However, they did encounter a rich learning environment in which they were exposed to new ideas. Additionally, due to the practice-driven nature of the course and the opportunities students had to conduct actual fieldwork, the students were able to experience the complex challenges of ethics in practice, not just as bystanders. This paper seeks to share the experiences of these budding practicing anthropologists so they can be used as a learning tool for generations to come.

\section{How ethics were incorporated into the course design}

Initial class discussion of ethics

Ethical considerations were incorporated into the course design in several different ways. First, during the initial planning of the research project, Wasson invited students to identify and discuss the possible ethical issues that might be involved in conducting an applied project for a business client. This was one way in which students from different disciplines were brought into a shared conversation on ethics as practiced in the anthropological tradition. 
Students focused on two main ethical issues. One was the recognition that a client like Motorola sponsors research for the purpose of increasing its sales. So, in a way, the class project would be promoting consumption. Students noted critiques of American society as being too consumption-oriented already, and expressed concern about contributing to this trend (Miller 2001). However, as their discussion progressed, they ended up differentiating among the consumption of different kinds of products; students concluded that while they would not want to promote the consumption of some items, they felt comfortable promoting media use to support cooking activities. More generally, they reflected on how to draw the line between products whose promotion would be ethical and those that would not be ethical. They realized that it was a personal decision; each anthropologist would probably draw the line a bit differently based on their biases and priorities. Students discussed whether or not it would be ethical to promote products which had the potential to cause harm to a person's health, if consumed in large quantities, such as sugary drinks, junk food, and alcohol. Other students noted that the decision to abuse products remained with the consumer, and ethical practitioners could contribute in a positive way to counteract misuse such as in the design of responsible advertising. An important outcome of this discussion was their realization that they should reflect now on where they wished to position their personal ethical boundaries, so that they would be prepared later when they were hired for work.

A second potential ethical issue that students raised was the payment of research participants. Students initially wondered whether it might bias study results. After discussion, they concluded that it was actually more ethical to pay research participants than to impose on their time without any form of recompense, as would be more common in traditional kinds of anthropology. This discussion opened a broader critique of the historical model of anthropological fieldwork in which researchers benefit by obtaining material for publication, while the research participants do not receive reciprocal benefits (Fluehr-Lobban 2008).

\section{Safeguarding the confidentiality of study participants and fieldwork data}

In developing courses that include client projects, Wasson always builds a set of ethical safeguards into the design of the course. One important consideration is to make sure that the client recognizes and is willing to honor the ethical concerns and commitments of anthropological research, with regard to the confidentiality of study participants, the protection of fieldwork data, and indeed the ownership of the data. When the main client contact has a background in engineering or business studies, this may require a process of education and relationship development. Fortunately, the client for this project was an anthropologist, Crysta Metcalf, so Wasson did not need to go through the kinds of explanations that she might need to with someone from another background. Metcalf 
herself was highly sensitive to ethical concerns and had educated her multidisciplinary work group in anthropological norms concerning the treatment of study participants.

A second ethical safeguard that Wasson built into the course was to obtain approval for the client project from UNT's Institutional Review Board (IRB). The IRB process is mandated by American federal regulations for the protection of human research participants (DHHS 2009). All studies conducted by U.S. university faculty that constitute "research with human subjects" as defined by the regulations must be approved by the university's IRB before the research can begin. The application process is fairly detailed and somewhat bureaucratic, but it is valuable in ensuring that study participants go through a thorough informed consent process. From a pedagogical point of view, the IRB application process provided students with useful exposure to ethical regulations beyond anthropology. All students were required to complete an online training course developed by the U.S. National Institutes of Health on "Protecting Human Research Participants" as a condition for IRB approval of the class project. The IRB application form and informed consent form were shared with students, and they were invited to suggest improvements. These forms became useful models for some students later when they prepared IRB applications for their master's thesis research.

On a more practical level, Wasson safeguarded the confidentiality of study participants and fieldwork data by creating a data storage site that was password-protected. She also taught students the importance of making sure that all of the information they uploaded was protected. In order for students to be able to access data from any location, the storage site was created in WordPress. Students were quite vigilant about protecting data and on one or two occasions policed each other when someone forgot.

Finally, Wasson asked the class to use pseudonyms for the research participants. These pseudonyms were used on written documents, such as fieldnotes, as well as for the filenames of video clips, photos, and maps that were uploaded to the data storage site. Furthermore, in class discussions, students were asked to refer to the study participants exclusively by their pseudonyms. This was important as extensive class time was spent comparing data from different study participants in order to identify patterns in the fieldwork.

\section{Disclosure of findings}

A third kind of ethical consideration that was built into the course design was the sharing of research findings. This can be a challenging issue in business anthropology, since corporate sponsors of research often regard the findings as providing a competitive advantage that they do not wish to share with potential competitors, at least for several years. The secrecy of 
anthropological findings has been a controversial issue in debates about the ethical code of the American Anthropological Association (Baba 2009).

Wasson and Metcalf developed an approach to this issue that accommodated the needs of both Motorola and UNT. They worked with lawyers from both organizations to develop a legal agreement, which protected Motorola's right to profit from the findings of the class, and the students' and Wasson's right to publish freely. No restrictions were placed on what could be described in publications. Motorola did not require any non-disclosure agreements to be signed. The current article illustrates the publishing freedom that students and professor enjoy.

\section{The class project: fieldwork and analysis}

In this section we outline the fieldwork process used for the class project, as a context for the ethics case study in the following section. To take advantage of the range of disciplines in the class, as well as support a collaborative environment, students worked in cross-disciplinary pairs; usually this resulted in an anthropologist and a designer being partnered. This allowed for a greater level of learning, especially while in the field conducting the interview. The student pairs first selected a research participant from a list of names provided by a recruiter hired by Motorola. The teams of two then contacted their selected participant via email and/or phone call. It was during this first contact that the student researchers discussed with participants what would be expected of them. The research methodology had three main components: photo narratives, kitchen maps, and in-depth interviews.

\section{Photo narratives}

Photographs were used to discover what media devices participants were using in the kitchen and how those devices affected the cooking process. During the initial phone call, participants were instructed to take photographs of all the ways they use media devices throughout their cooking experiences for about a week. They were asked to email digital copies of the photographs to the student researchers throughout the week. A date and time for an in-home interview with the participant, during which the student researchers could further explore the meaning behind the photographs, were set up during this initial correspondence. Figure 2 provides some examples of photos taken by the study participants. The photograph on the left shows a participant preparing a meal with his laptop open to an instructional website. The photograph on the right shows a participant's iPad open to a cooking website, sitting on the kitchen counter. The photograph on the bottom shows the placement of a participant's laptop on the edge of the kitchen counter; this participant was very cautious in regards to subjecting the computer to 
accidental spills and everyday kitchen grime.

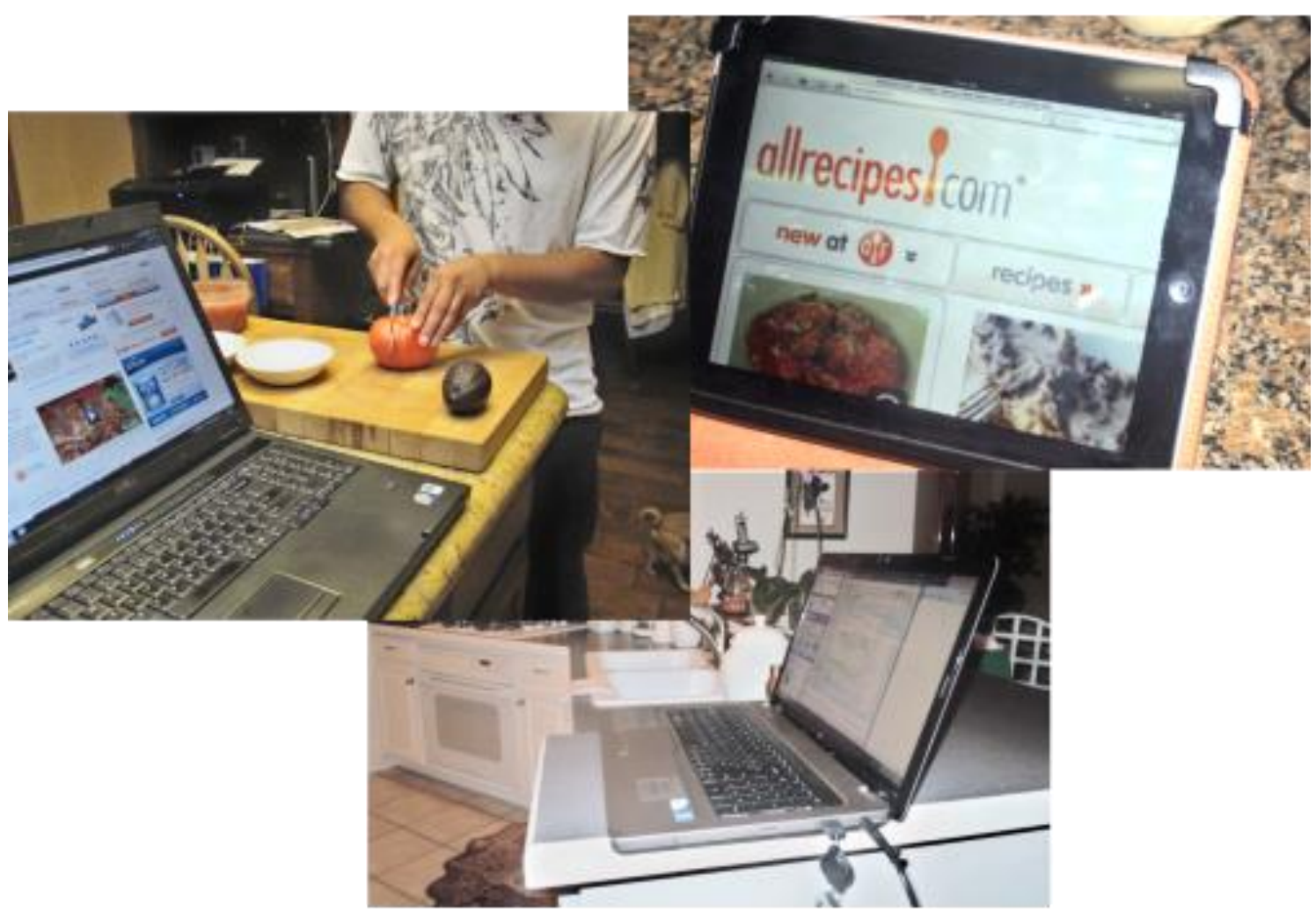

Figure 2: Sample photos

\section{Kitchen maps}

Research participants were also asked to draw a map of their kitchen during one particular cooking process. This was important for tracking the movement and use of media devices in the kitchen while cooking. Some participants used mobile devices (iPads, phones, and laptops), while others used more stationary devices (desktop computers and televisions). The kitchen maps allowed the students to see to what extent different media devices were being used. The maps were discussed during the interview with the research participants and were accompanied by a kitchen tour. Figure 3 provides an example of a map; noted on the map is the placement and movement of the participant's computer while cooking. 


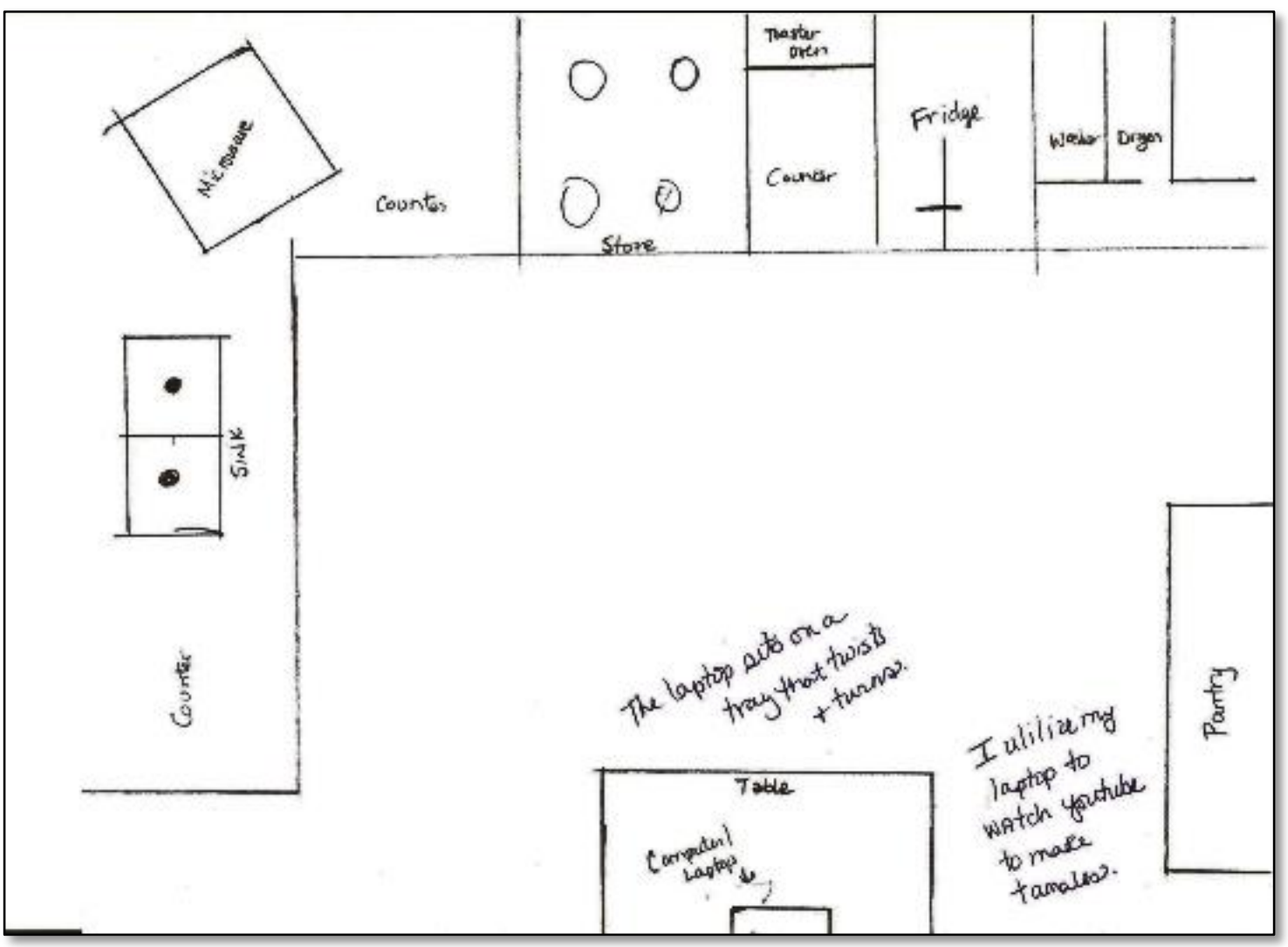

Figure 3: Sample kitchen map

\section{Interviews}

After receiving the photos and maps, student researchers conducted a semi-structured, in-depth interview with the research participant to explore his or her cooking process and the roles that media played in it. Interviews took place in the participant's home. An effort was made to schedule the interview no later than a week after the participants had submitted their photographs and kitchen map. An interview guide was developed during class time and with the input of every class member. It was used, along with the photo narratives and the kitchen maps, to conduct the $1 \frac{1 / 2}{2}$ to 2 hour interviews, each of which was video recorded so it could later be re-watched and summarized by students. In the interviews, students paid special attention to how media devices were used at each stage of the cooking process, before, during, and after.

\section{Analysis}

Analysis of the interviews began with each team presenting their individual participant findings to the rest of the class, using a PowerPoint with video clips, maps, and photos. This allowed each team to present to the class what they found interesting and pertinent from their personal interview experience to the research question at hand. Class presentation of insights from each participant also allowed the rest of the class to begin 
identifying common patterns and themes throughout all of the interviews. All participant photos, important video clips, field notes, interview transcripts, and kitchen maps were posted on the password-protected data storage site described earlier. This provided the students, professor, and Motorola contacts with easy, secure access to all of the project documents.

As the student teams started to present their findings, a Word document was created in which all themes and patterns that emerged in class discussion were logged. During subsequent weekly class meetings, this Word document was expanded and reworked until the most important and valid patterns across the interviews were identified. It was very important for each of the 16 students' voices to be heard; the analysis was truly a class effort. The input and insights from the designers and anthropologists melded together to form the most complete picture possible.

\section{Ethical challenges of fieldwork: an extreme case}

Ethics has been a frequent topic of deliberation for business anthropologists since the resurgence of applied work concerning organizations during the 1980s. In the inaugural issue of this journal, Marietta Baba notes that ethics is one of "our discipline's major issues at this time" (Baba 2012:24).While most debates concerning ethics in business anthropology focus on the issues of conducting proprietary research and balancing the client-researcher relationship (Hammershøy and Madsen 2012), ethical dilemmas concerning fieldwork are common topics of discussion throughout the field of anthropology (Arnould et al. 2012).

Anthropological fieldwork is characterized by interactions with communities, societies, and various cultural groupings. The humanistic nature of anthropological fieldwork makes it imperative for the researcher to display moral and ethical behavior befitting human subject research. As a result, the American Anthropological Association (AAA), the National Association for the Practice of Anthropology (NAPA), and the Society for Applied Anthropology (SfAA) have adopted codes of conduct and guidelines to address ethical considerations before, during, and after ethnographic fieldwork. The guidelines established by these professional associations uphold the standards issued by the United States Code of Federal Regulations on the Protection of Human Subjects (DHHS 2009). Subpart A of the regulations, referred to as the Common Rule, establishes the criteria to be followed by IRBs and federal grant agencies. These criteria are familiar to anthropologists in and outside of academia.

However, while ethical codes provide important guidance, they cannot predict every situation that arises in the field. Their seeming clarity may mask the murkier reality that is inevitably experienced by 
every ethically concerned fieldworker. In the complex, multifaceted encounters that arise between research participants and anthropologists, identifying the right course of action is not always easy. There may be complex trade-offs, multiple potential sources of harm to participants that cannot all be avoided.

We describe one such case, and its value as a learning experience for the Design Anthropology class, as well as for readers of this article. The case constituted a kind of "perfect storm" of problematic elements, and as such may be characterized as an extreme case. The notion of the extreme case has a long history in the social sciences. It formed the basis for Mauss 's argument in "Seasonal Variations of the Eskimo" that he could develop generalized social laws from a single case study ([19041905] 1979).

"We have chosen this remarkable people as the special object of our study precisely because the relations to which we wish to call attention are exaggerated and amplified among them; because they stand out, we can clearly understand their nature and significance. As a result, it is easier to recognize them even in other societies where they are less immediately apparent."

(Mauss [1904-1905] 1979:19)

Subsequently other ethnographic studies have been organized around extreme cases. For instance, Dumont developed a conceptualization of "homo hierarchicus" by examining caste in India as an extreme form of social hierarchy ([1966] 1980). Klinenberg examined the dangers of urban life for vulnerable populations by analyzing causes of the recordbreaking mortality rate of the 1995 Chicago heat wave (2002). The value of extreme cases is regularly described in books on social science methods (LeCompte and Schensul 1999:113, Yin 2009:47). We apply the notion of the extreme case to the topic of fieldwork ethics.

\section{Research participant "Rev" as an extreme case}

Rev was the last study participant interviewed by the class, and her team of student researchers had faced a number of obstacles before even getting to that point. The team consisted of Jo Aiken, an MA anthropology student and one of the authors of this article, and Rebeca Carranza, an MFA design student. Both were first semester graduate students and had attended Texas A\&M University as undergraduates. They instantly connected due to their shared alma mater and developed a deeper rapport due to their shared challenges early on in the project.

Aiken and Carranza were never able to reach the first study participant they were assigned due to insufficient contact information. The second participant they were given withdrew from the study after twice cancelling scheduled interviews. By the time they were given their 
third research participant, Rev, the project was nearing the end of its data collection phase, and obtaining this final interview had become urgent. Aiken and Carranza scheduled an interview with Rev in late November, at the earliest possible opportunity, even though the time overlapped with the weekly class meeting.

The face-to-face interview with Rev proved to be an on-the-job learning experience for both Aiken and Carranza. From the moment Rev greeted them at the door of her home, it was obvious to both students that their interviewee seemed exceptionally happy about participating in the study. Aiken's initial impression was that Rev just had a bubbly personality. However, both students gradually developed the impression that Rev might be intoxicated. Aiken and Carranza each struggled internally, without the ability to speak to one another openly in front of their participant, with the decision of whether to carry on with the interview. They proceeded with it because, in their best judgment, Rev still had the capacity to understand the research activities she was participating in. However, the situation was ambiguous. Later, both students admitted that they could not know for sure if in fact Rev was intoxicated or at what level. Her speech was slightly slurred in comparison to their two previous phone conversations, and the open bottles and empty martini glass on the bar adjacent to the dining table where they conducted the interview supported their suspicion. Yet the two phone calls Carranza had with Rev did not offer any indication that she was intoxicated on a regular basis.

With reservations, Aiken and Carranza continued Rev's interview. Halfway through it, Rev's daughter joined her mother at the dining room table where the interview was taking place. The daughter appeared to be approximately 11 to 13 years of age. She came to the table of her own accord - a bored, hungry teenager coming to the kitchen wondering when dinner would be ready. Sitting down next to Rev, the daughter first listened quietly and then joined in the conversation when prompted by her mother to answer certain interview questions. The exchange between the mother and daughter was casual. It appeared that Rev was trying to include her daughter in a friendly conversation with visitors, rather than encouraging her to participate in a study. Aiken, the primary interviewer, was immediately concerned when Rev began redirecting questions to her daughter since the class had not obtained IRB consent for interviewing minors. Even though her mother was present and apparently consenting to her daughter's involvement in the study, Rev's possibly inebriated state brought the circumstances into question. Carranza, in charge of videotaping the interview, was also concerned about the consequences of a minor being on record for the study. Again, without the ability to communicate openly with each other, Aiken and Carranza continued with the interview as planned, making sure to redirect fielded questions back to their adult participant, Rev. 
Aiken and Carranza repeatedly reflected on whether they should continue the interview while it was taking place. Each of them felt it was best to continue for several reasons. Most importantly, to stop the interview would have meant passing judgment on Rev as a responsible adult and as a mother. As they later shared with each other, they felt it was a moral obligation to withhold their own judgments about Rev's unconfirmed inebriated state and her parenting choices, and that to stop the interview would have caused more harm to the participant's feelings than would continuing with it. Another consideration for Aiken was that Rev would not receive compensation for participating in the study if they stopped the interview. The students were instructed to present the research payment to participants only at the conclusion of the interview. Stopping it did not seem fair to Rev, who had already devoted hours of her week to completing the other tasks she was assigned, such as taking photos and mapping her kitchen experiences. Also, Aiken and Carranza felt a responsibility to report their findings to Motorola and the Design Anthropology class. Aiken felt confident that Wasson would allow them to make up the grade for the interview, but she did not want to let down Metcalf and the class by decreasing the total population of the study.

\section{First ethically gray area: a potentially intoxicated research participant}

The ethically gray area surrounding Aiken and Carranza's dealings with their participant Rev in her possible intoxicated state can be examined in terms of vulnerability and research design. Since the drafting of the Nuremburg Code in 1947, obtaining the fully informed consent of research participants has been at the forefront of concerns in ethical research. As a result, if the research design necessitates the inclusion of vulnerable participants incapable of providing informed consent, special provisions have to be made. Guidelines to these provisions are laid out in federal policies and professional codes.

There are many varying guidelines within medical research and healthcare aimed at protecting the vulnerable. While various definitions exist, the federal regulations which generally impact the research of business anthropologists in the U.S. are the Code of Federal Regulations for the Protection of Human Subjects (DHHS 2009) and, if conducted within academia, the Office for Human Research Protections (OHRP) IRB Guidebook (OHRP 1993). The Federal Policy for the Protection of Human Subjects - often referred to in government documents as the Common Rule or simply, Federal Policy - sets forth the basic guidelines for research concerning human subjects conducted or supported by the U.S. Department of Health and Human Services (DHHS) and establishes the need for additional safeguards when dealing with populations incapable of giving informed consent, or those susceptible to coercion (DHHS 2009). Under the term vulnerable populations, the Common Rule states that special provisions have to be made to protect the rights and welfare of these groups when involved in research. The Common Rule classifies 
children, prisoners, pregnant women, mentally disabled persons, and economically or educationally disadvantaged persons as vulnerable populations. The OHRP, which governs the IRBs for all universities that accept federal funding, reaffirms the vulnerable populations identified in the Common Rule in its IRB Guidebook, but also reclassifies populations as special classes of subjects (OHRP 1993).

Although the federal guidelines have not been unanimously adopted verbatim by all federal agencies, professional associations of disciplines involved in human subject research generally uphold the Common Rule in practice. However, at the time of the kitchen media study in 2011, the ethical codes and professional guidelines of the AAA, NAPA, and SfAA did not specifically list vulnerable populations or special classes of subjects (AAA 2009, NAPA 2013, SfAA 2013). In 2012, the AAA approved changes to their Code of Ethics that included adding the recognized legal term vulnerable populations, yet the Code does not offer a definition of the term or a list of included groups (AAA 2012).

In light of the differences in population classifications and research approaches, the dilemma surrounding Rev's intoxication can be evaluated according to both clinical and ethnographic standards. Chapter VI of the OHRP's IRB Guidebook further specifies the Common Rule's vulnerable population "mentally disabled persons" (OHRP 1993, Chapter VI) to include cognitively impaired individuals with "psychiatric, cognitive, or developmental disorders, or who are substance abusers" (OHRP 1993, Chapter VI, part D). The Guidebook states that the basic principle for safeguarding these individuals is "that their disorders may compromise their capacity to understand the information presented and their ability to make a reasoned decision about participation" (IRB Guidebook Chapter VI, part D). The Guidebook goes on to suggest that persons under the influence of drugs or alcohol should also be evaluated according to their competency in providing consent, but the OHRP does not set specific regulations for these persons except in the case of known, active abusers. The IRB Guidelines outlined by the University of North Texas, which has fully adopted the Common Rule and the DHHS's guidelines, goes further by stating that "all adults, regardless of their diagnosis or condition, should be presumed competent to provide informed consent unless there is evidence" (UNT ORED 2013). In accordance with the IRB Guidebook, Rev's competency to provide informed consent should then be determined, based on the researchers' judgment of her capacity to understand information in her intoxicated state if she was not an active substance abuser. The Guidebook does not outline the means by which a researcher independently determines a participant to be an active substance abuser. Rev was not institutionalized - a situation that the Guidebook addresses - at the time of the interview, and previous phone calls did not give the research team any indication of cognitive impairment or active substance abuse. Therefore, the question of Rev's competency could only be answered by Aiken and Carranza by evaluating 
her capacity to understand information. Rev had no difficulty in understanding the interview questions, the photo narrative, or the kitchen tour, and at no point indicated incapacity to consent to the process.

The AAA, NAPA, and SfAA professional associations also place the judgment of a participant's capacity to consent, outside general circumstances, with the individual researcher. The means of determining capacity, as in the Common Rule and the IRB Guidebook, are not laid out in their ethical codes. Keeping in mind anthropological paradigms of building rapport and reflexivity, it is doubtful that these associations would support researchers administering breathalyzer tests to their participants on a regular basis, nor would they encourage researchers to question participants based on a hunch. In fact, intoxication is often an important part of the ethnographic research design. Cultural and applied anthropologists often conduct studies of drinking cultures and other groups in which drinking plays a vital role (Frake 1964, Garcia 2008, Sandiford and Seymour 2013, Spradley 1999). When alcohol is not pertinent to the research question, ethnographers have noted that intoxication often aids in building rapport with participants (Joseph and Donnelly 2012). anderson and DePaula (2006) describe a significant experience they had with an intoxicated group of Portuguese locals on an inter-island boat ride home after a long day of work. Even though their research in Salvador da Bahia, Brazil was not targeted towards partakers of alcohol and even though the encounter was unintentional, the experience added to their research on the collective nature of the culture (anderson and DePaula 2006).

Like anderson and DePaula's study, the kitchen media study did not intend to include intoxicated participants. Aiken and Carranza were not uncomfortable with the interview because of a moral judgment against alcohol in and of itself, but because they were unsure about Rev's mental state and how it would affect their findings. The question of how to handle cognitively impaired participants did not come up in the ethical discussions in class because the research design did not specifically target such populations. Since the interview posed no more than the least amount of minimal risk to the participant, the student researchers completed the interview with the understanding that Wasson or Metcalf could choose to eliminate the data from the study.

\section{Second ethically gray area: an unapproved child joins the interview}

The ethical dilemma concerning Rev's questionable demeanor during the interview was magnified when her daughter joined the interview. Rev's daughter was undoubtedly a minor by federal standards. The Common Rule and the OHRP's IRB Guidebook (OHRP 1993) leave the determination of legal age of consent to the local laws within which research is conducted. The State of Texas, under which the jurisdiction of 
the kitchen media study fell, considers a child to be any person under the age of 18 (Texas Civil Practice and Remedies Code 1985). There was no question that Rev's daughter was a minor, and there was no question in the minds of the student researchers that special precautions should be taken to protect children participating in research.

As described earlier, Rev's daughter sat down at the table voluntarily. Her mother introduced Aiken and Carranza as the students conducting the kitchen study, a study her daughter was apparently already aware of. Rev mentioned that her daughters, plural, found the week leading up to the interview fun because their mom was taking pictures of all their meals. As for the daughter's mental capacity to understand the research situation, there was no question that she was capable of understanding her surroundings and the risks involved from participating in the research. However, the Federal Policy (DHHS 2009) concerning the involvement of children as subjects stipulates that legal consent be obtained in writing by at least one parent or guardian. Rev had not provided written consent for her daughter's participation, even though she was the one who instigated the daughter's involvement in answering the interview questions.

Nevertheless, the flow of the interview brings into question whether or not the child was actually participating in the kitchen media study, and if the student researchers were in violation of federal policy. The Federal Policy states that "no investigator may involve a human being as a subject in research... unless the investigator has obtained the legally effective informed consent of the subject or the subject's legally authorized representative" (DHHS 2009). The Federal Policy notes the involvement of a research subject by an investigator. Rev's daughter was not at any point considered by the student researchers to be a subject of the study. Consent was not obtained prior to the study because there was no intention of involving the daughter, or any child, in the study. The Federal Policy and the IRB Guidebook outline provisions for studies in which the intent of the use of human subjects changes as a result of the research design. However, the student researchers did not involve the child in the interview. The mother, Rev, repeated an interview question, or portions of a question, to her daughter and asked for her thoughts on the subject. The daughter, it could be argued, was engaging in conversation with her mother rather than engaging in a research study. The responses from the child were not transcribed, or included in the research findings or the final report. Although glimpses of the child appeared in the video of the interview due to the close proximity of the interviewee and her daughter, no images of the child were used in any presentation or publication. Rev's daughter contributed in no way to the kitchen media study.

Aiken and Carranza's decision to continue with the interview weighed heavily on their minds during the three to four minutes she was 
present. Even though the mother apparently consented to her daughter's involvement and the child was apparently capable of providing assent, they were aware of the ethical issues in involving children in research studies. One issue, susceptibility to coercion, did not appear to be of concern in this particular situation. The child sat down at the dining room table where the interview was being conducted without being asked to by her mom. When the child responded to her mother's questions with the typical teenage "I dunno," Rev did not scold her daughter or entice her in any way. Based on Aiken and Carranza's judgment of the situation, the child was in no danger or was in anyway being harmed by their presence.

\section{Conclusion: navigating the gray areas}

The extreme case of the participant Rev not only provided a learning experience to the student team that conducted her interview, but also opened class discussion on navigating the ethically gray areas in ethnographic research. Based on class discussions as well as further conversations at the 2012 AAA session on ethics in business anthropology where this research was initially presented, we offer three conclusions regarding ethical encounters in anthropological research.

\section{Ethically gray areas can occur in any research, no matter how well planned}

Prior to the start of fieldwork, the kitchen media study was carefully reviewed for its ethical soundness by Metcalf, Wasson, the UNT IRB, and the students in the design anthropology class. Everyone agreed that it did not pose risks to the research participants. The population of research participants did not include categories of vulnerable persons such as children, prisoners, mentally disabled persons, or economically or educationally disadvantaged persons (DHHS 2009). The fact that the situation with Rev nonetheless occurred illustrates the point that any study involving human subjects, no matter how carefully designed, can produce ethically gray areas. There is always an unpredictable aspect to human interactions due to the complexity and multifacetedness of human agency as well as the diverse institutions and social processes we navigate.

\section{Ethically gray areas occur for seasoned anthropologists and students alike}

Much to Aiken and Carranza's relief, Wasson assured her students that even the most seasoned anthropologists are not exempt from dealing with ethically gray areas. Students and their mentors share in the agony of ethical dilemmas encountered in the field. Anthropologists, perhaps more than any group of researchers, understand and appreciate the diversity and often unpredictable nature of human behavior. As long as 
humans remain diverse and unpredictable, ethically gray areas are sure to arise. Ethics will remain a subject of concern as humans continue to evolve and adapt their behaviors. In fact, the special issue of this journal proves the prevalence of ethical debate within anthropology today.

\section{Ethically gray areas are experienced across disciplines}

Although this research was originally presented in a 2012 AAA session on ethics in business anthropology, gray areas are not limited to business anthropology. The lively discussion that followed the presentation of papers in this session included audience members who specialized in a range of different areas. Yet they shared a broad agreement on the kinds of ethical challenges they faced. Furthermore, the discipline of anthropology shares ethical considerations with other social and biological sciences as well as with any discipline that seeks to engage with human participants.

\section{Ideas for solutions: preparing for the unpredictable}

The kitchen media study conducted for Motorola during the Fall 2011 Design Anthropology course at UNT resulted in valuable findings for the client and valuable lessons in ethics for the class. In particular, the interview with Rev opened the class to conversations regarding ethically gray areas of field research which can vary across disciplines. The practical lessons learned are not only applicable to a class of interdisciplinary students, but also serve as points of discussion for seasoned researchers. Although ethically gray areas are by definition undefinable, the authors offer ideas for solutions in preparing for the unpredictable.

First and foremost, we suggest that researchers should strive to avoid complacency as they move forward in their careers. Where students have the advantage over seasoned anthropologists is the advantage of novelty. Shocking stories of human research programs which initiated the development of ethical guidelines are usually heard first in the classroom. As ethics continues to be taught in graduate programs, students are exposed to ethical considerations through coursework and classroom discussions. For many students, the classroom is the first and possibly the last environment which requires their review of literature regarding ethics.

In order to avoid complacency, professional anthropologists should endeavor to regularly review ethical standards. As students are constantly reminded by their coursework, seasoned anthropologists should stay up to date on ethical debates, including the consistent revisiting of professional guidelines such as the American Anthropological Association's Statement on Ethics and the Society for Applied Anthropology's Ethical and Professional Responsibilities as well as those of other disciplines with which they work. 
Furthermore, as anthropologists, we are aware that the cultures of our study participants may have different conceptualizations of ethical behavior from the American-based AAA Statement on Ethics. The debate between cultural relativism and universalism is ongoing in anthropology in relation to topics such as human rights.

"Should not global research be met by global ethics or a vigorous discussion and debate of what our universal standards of ethical conduct are? ... Have non-Western anthropologists achieved agency in the international discourse of ethics and professionalism, or is this yet another piece of the unfinished business of colonialism and its fallout?"

(Fluehr-Lobban 2013:18)

While there are no simple answers to such questions, it is useful for practitioners to reflect on them and develop their own personal guidelines.

Finally, we suggest that anthropologists could share their stories of encounters with ethically gray areas within their communities of practice. Although it is unlikely that extreme cases of ethically gray areas will be experienced repeatedly in the same manner, storytelling is a valuable tool in preparing researchers in any discipline for adventures in the field.

Sharing Rev's story provided a learning opportunity for all the students in the design anthropology class on how to manage ethical dilemmas, and allowed the class to discuss ways in which to handle ethically gray areas. Such stories of extreme cases not only offer lessons learned to students, but can also open lines of communication among seasoned anthropologists. By sharing stories, students and professional anthropologists are given the opportunity to learn from another's experience in the field while also discovering that ethically gray areas are a shared, acceptable subject of discussion.

\section{References}

American Anthropological Association (AAA). 2012. Statement on Ethics: Principles of Professional Responsibility. http://www.aaanet.org/profdev/ethics/, accessed February 3, 2013.

American Institute of Grapic Arts (AIGA). 2010. Standards of Professional Practice. http://www.aiga.org/standards-professionalpractice/, accessed February 14, 2013.

andersen, ken, and Rogério De Paula. 2006. We We We All the Way Home The We Affect in Transitional Spaces. Ethnographic Praxis in Industry Conference, 2006. Vol. 2006, pp. 60-75. Blackwell Publishing Ltd. for the American Anthropological Association. 
Armbruster, Heidi, and Anna Laerke, eds. 2008. Taking Sides: Ethics, Politics and Fieldwork in Anthropology. New York: Berghahn

Books.

Arnould, Eric J., Becker, Howard S., Boyer, Dominic, Hannerz, Ulf, Lien, Marianne, Löfgren, Orvar, Marcus, George E., Morais, Robert J., Nakamaki, Hirochika, and Alan Smart.2012. Opinions: What Business Anthropology is, What it Might Become... And What, Perhaps, It Should Not Be. Journal of Business Anthropology 1(2):240-297.

Baba, Marietta L. 2009. Disciplinary-Professional Relations in an Era of Anthropological Engagement. Human Organization 68(4):380-391.

Balsamo, Anne, and Carl Mitcham. 2012. Interdisciplinarity in Ethics and the Ethics of Interdisciplinarity. In The Oxford Handbook of Interdisciplinarity. R. Frodeman, J.t. Klein, and C. Mitcham, eds., pp. 259272. Oxford: Oxford University Press.

Dumont, Louis. 1980 (1966). Homo Hierarchicus: The Caste System and its Implications. M. Sainsbury, L. Dumont, and B. Gulati, transl. Chicago: University of Chicago Press.

Fluehr-Lobban, C. 2003. Ethics and Anthropology 1890-2000: A Review of Issues and Principles. In Ethics and the Profession of Anthropology:

Dialogue for Ethically Conscious Practice. 2nd edition. C. Fluehr-Lobban, ed., pp. 1-28. Walnut Creek: AltaMira Press.

Fluehr-Lobban, C. 2008. Collaborative Anthropology as Twenty-FirstCentury Ethical Anthropology. Collaborative Anthropologies 1:175-182.

Fluehr-Lobban, C. 2013. Ethics and Anthropology: Ideas and Practice. Walnut Creek: Altamira Press.

Frake, Charles 0.1964. How to Ask for a Drink in Subanun. American Anthropologist 66(6):127-132.

García, Victor. 2008. Problem Drinking Among Transnational Mexican Migrants: Exploring Migrant Status and Situational Factors. Human organization 67(1):12-24.

Hammershøy, Laura, and Thomas Ulrik Madsen. 2012. Ethics in Business Anthropology. Ethnographic Praxis in Industry Conference Proceedings, 2012. Vol. 2012, pp. 67-73. Wiley Online Library.

Industrial Designers Society of America (IDSA). 2010. Code of Ethics. http://www.idsa.org/content/content1/code-ethics/, accessed February 14, 2013.

Ikeya, N., Vinkhuyzen, E., Whalen, J., and Y. Yamauchi. 2007. Teaching Organizational Ethnography. In Ethnographic Praxis in Industry Conference, pp. 270-282, Vol. EPIC 2007.

Joseph, Janelle, and Michele K. Donnelly. 2012. Reflections on Ethnography, Ethics and Inebriation. Leisure/Loisir 36(3-4):357- 
372.

Kingsolver, A., Wagner, G., Barrera, R., Bennett-Brown, J.C., Clark, D., Gerald, V.D., Goodrich, D., Hewlett, M., Hughes, M., Leader, J., Liger, L., Little Water, T., Loftlin, C., Parra-Medina, D., Rymer, D., Scott, C., Shumpert, C., Thompson, G.N., and T. Wilson. 2003. Teaching Anthropological Ethics at the University of South Carolina: An Example of Critical Ethical Dialogues Across Communities. In Ethics and The Profession of Anthropology: Dialogue for Ethically Conscious Practice. 2nd edition. C. Fluehr-Lobban, ed., pp. 197-224. Walnut Creek: AltaMira Press.

Mack, Alexandra, and Susan Squires. 2011. Evolving Ethnographic Practitioners and Their Impact on Ethnographic Praxis. In Ethnographic Praxis in Industry Conference, pp. 18-28, Vol. EPIC 2011.

Mauss, Marcel. 1979. Seasonal Variations of the Eskimo: A Study in Social Morphology. Translated by J.J. Fox. London: Routledge \& Kegan Paul.

Miller, Daniel. 2001. The Dialectics of Shopping. Chicago: University of Chicago Press.

Moeran, Brian. 1985. Okubo Diary: Portrait of a Japanese Valley. Stanford: Stanford University Press.

National Association for the Practice of Anthropology (NAPA). 2013. NAPA Ethical Guidelines.

http://practicinganthropology.org/about/ethical-guidelines/, accessed January 10, 2013.

Office for Human Research Protections (OHRP). 1993. IRB Guidebook. http://www.hhs.gov/ohrp/archive/irb/irb_guidebook.htm, accessed February 20, 2013.

University of North Texas Office of Research and Economic Development (UNT ORED). 2013. IRB Guidelines. http://research.unt.edu/facultyresources/research-integrity-and-compliance/use-of-humans-inresearch/, accessed February 14, 2013.

Sachs, Patricia. 2006. Bushwacking a Career. NAPA Bulletin 26:152-162.

Sandiford, Peter John, and Diane Seymour. 2013. Serving and Consuming: Drink, Work and Leisure in Public Houses. Work, Employment \& Society 27(1):122-137.

Society for Applied Anthropology (SfAA). 2013. SfAA Ethical and Professional Responsibilities. http://www.sfaa.net/sfaaethic.html, accessed January 10, 2013.

Spradley, James P. 1999. You Owe Yourself a Drunk: An Ethnography of Urban Nomads. Waveland Press.

Squires, Susan, Christina Wasson, and Ann Jordan. 2014. Training the Next Generation: Business Anthropology at the University of North 
Texas. In Sourcebook of anthropology in business. R. Denny and P. Sunderland, eds. Walnut Creek: Left Coast Press.

State of Texas. 1985. Age of Majority. Title 6, Chapter 129, Section 129.001: State of Texas.

Tian, Robert G. 2011. We Need Business Anthropology Education: Editorial Commentary. International Journal of Business Anthropology $3(1)$.

Wasson, Christina, and Crysta Metcalf. 2013. Teaching Design Anthropology Through University-Industry Partnerships. In Design Anthropology: Between Theory and Practice. W. Gunn, T. Otto, and R.C. Smith, eds. London: Berg.

Yin, Robert K. 2009. Case Study Research: Design and Methods. Los Angeles: Sage Publications.

Jo Aiken (MA Candidate in Applied Anthropology, University of North Texas) is focusing her research on design anthropology and its application to technology development, expert communities of practice, and "innovation." She recently completed research for her master's thesis on privacy needs and habitat design for long duration spaceflight with the NASA Johnson Space Center. She will begin her doctoral studies in Anthropology at the University College London in the fall of 2014. She can be reached at JonieAiken@gmail.com, or on Twitter @jo_aiken.

Victoria Schlieder (MS Candidate in Applied Anthropology, University of North Texas) is just beginning her career as a business anthropologist. She is particularly interested in examining the consumer experience as a way to help retailers and merchandisers, both big and small, succeed. She has conducted research on declining retail establishments and what can be done to revitalize them, including a study of a 'dead mall' and her master's thesis research on retail businesses in downtown Bloomsburg, Pennsylvania. She may be reached at victoriaschlieder@my.unt.edu.

Christina Wasson (Professor of Anthropology, University of North Texas) developed the only design anthropology course offered through an anthropology department, as part of UNT's focus on business anthropology. A linguistic anthropologist, her passion is investigating communication, collaboration, and community-building, both face-to-face and online. She may be reached atcwasson@unt.edu. 